\title{
Blood carbon monoxide levels as a function of daily cigarette consumption and physical activity
}

\author{
L. H. HAWKINS \\ University of Surrey, Department of Human Biology and Health, Guildford, Surrey
}

Carboxyhaemoglobin concentrations $(\mathrm{COHb})$ have been measured in groups of individuals smoking while engaged in different activities. The three groups chosen (meat porters, office workers, and pregnant women) had finger-prick blood samples taken at about six hours into their working day. $\mathrm{COHb}$ was measured by the method of Commins and Lawther (1965), a method subsequently shown to have a mean error of $0.67 \%$ (SD 0.65) in the range $0-40 \% \mathrm{COHb}$ (Lily, Cole, and Hawkins, 1972). A highly significant difference $(\mathrm{P}<0.005)$ was found between the $\mathrm{COHb}$

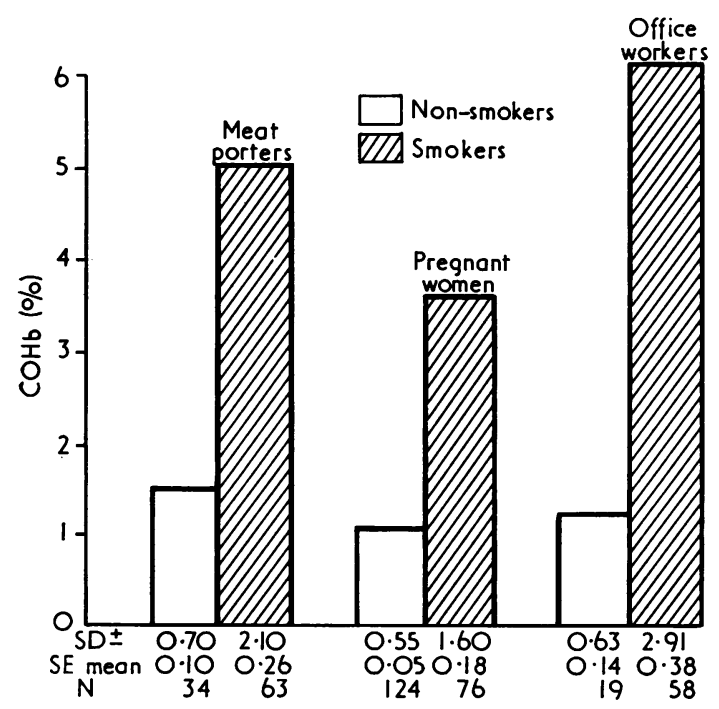

FIG. 1. Mean carboxyhaemoglobin levels of smokers and non-smokers in the three groups of individuals, and relevant statistics. levels of smokers and non-smokers within each group. Fig. 1 shows the extent to which smoking outweighs urban air pollution or endogenous production as a source of carbon monoxide.

Fig. 2 shows the relationship of blood $\mathrm{COHb}$ (C) to the numbers of cigarettes smoked per day (n). Curves of the form $\mathrm{C}=\frac{\beta(\gamma+\mathrm{n})}{\alpha+\gamma+\mathrm{n}}$ were fitted, values of the constants $\alpha, \beta$, and $\gamma$ being determined so as to minimize the sum of the squared deviations of $\operatorname{Ln}(\mathrm{COHb} \%+1)$.

The treatment of the data is to be described more fully elsewhere (Hawkins, Cole, and Harris, 1976).

Pregnant women and meat porters show a very similar relationship between $\mathrm{COHb}$ and smoking rate (Fig. 2D) In both cases the curves plateau such that above 25 cigarettes per day there is very little increase in $\mathrm{COHb}$ for increasing numbers of cigarettes smoked. The results suggest that the meat porters who were engaged in physical exertion while smoking and the pregnant women (in whom cardiorespiratory adjustments simulate exercise, Cugell et al., 1953), reach an equilibrium at about $5 \% \mathrm{COHb}$ after which uptake of $\mathrm{CO}$ during smoking is more or less equal to elimination in the non-smoking periods. The office workers, who were sedentary while smoking, show a curve rising towards a considerably higher asymptote, well above the range sampled.

Sedentary smoking appears to allow a much greater accumulation of carbon monoxide from cigarette smoke, than is found in active smokers. Two factors were considered that might have influenced this interpretation. The possibility that meat porters and pregnant women smoked fewer cigarettes than the office workers was considered. At the time of sampling each subject was asked how many cigarettes he or she had smoked so far that day. 


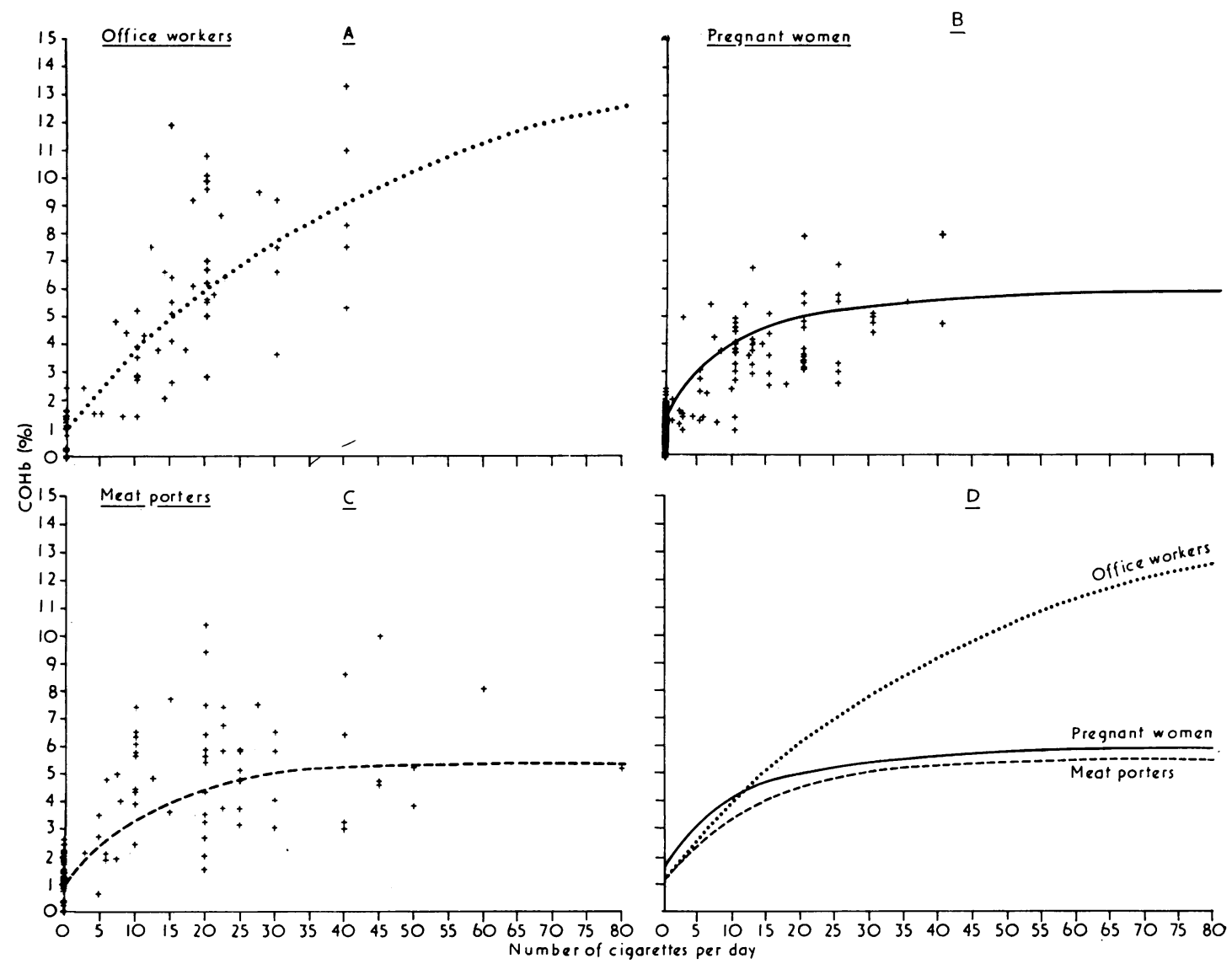

FIG. 2A, B, C. Computer-produced scattergrams of the three sets of data. The derived curves are superimposed and also shown in relation to one another in $\mathrm{D}$.

With respect to the daily consumption rate there was no significant difference between the groups in the number of cigarettes smoked up to the time of sampling, indicating that occupation was neither a deterrent nor a stimulus to smoking.

Sex differences between the groups were also considered. Two of the groups were exclusively single sex (meat porters and pregnant women) while the office workers were mixed $(53 \%$ female, $47 \%$ male). Separating male from female office workers showed that there was no difference between them in $\mathrm{COHb}$ with respect to daily consumption rate. The women, however, smoked fewer cigarettes on average per day than the men.

These results are of some relevance to the recent interest concerning smoking and COHb. Russell has suggested that a more realistic goal for smoking and health education would be to persuade people to smoke more safely and less, rather than to advocate abstention (Russell, 1974). The present results suggest that active people who smoke who are being advised to reduce cigarette consumption should do so to well below 25 cigarettes a day in order to reduce their mean $\mathrm{COHb}$ level. Sedentary smokers appear to be able to reduce their $\mathrm{COHb}$ level by any reduction in cigarette consumption, although it must be borne in mind that sedentary smokers have much higher blood levels of $\mathrm{COHb}$ than active smokers.

One aim of trying to achieve safer smoking must be to reduce blood levels of $\mathrm{COHb}$ since there is evidence that $\mathrm{CO}$ is implicated in the aetiology of cardiovascular disease (Astrup, Kjeldsen, and Wanstrup, 1967; Kjeldsen, 1969; Birnstingl, Hawkins, and McEwan, 1970; Wald et al., 1973), and in some of the consequences of smoking during pregnancy (Cole, Hawkins, and Roberts, 1972). The evidence suggesting a relationship between cigarette smoking, occupation, and illness indicates that inactivity and cigarette smoking are positively related to the incidence of coronary heart disease (US Department of Health, Education and Welfare, 1973). It may well be that among other factors 
contributing to this effect, the higher blood $\mathrm{COHb}$ levels found in sedentary smokers are important.

I should like to acknowledge the participation of Dr P. V. Cole in the collection of the data reported here, and Dr J. Harris for help with the mathematical treatment.

\section{References}

Astrup, P., Kjeldsen, K., and Wanstrup, J. (1967). Enhancing influence of carbon monoxide on the development of atheromatosis in cholesterol-fed rabbits. Journal of Atherosclerosis Research, 7, 343-354.

Birnstingl, M., Hawkins, L., and McEwan, T. (1970). Experimental atherosclerosis during chronic exposure to carbon monoxide. European Surgical Research, 2, 92-93.

Cole, P. V., Hawkins, L. H., and Roberts, D. (1972). Smoking during pregnancy and its effects on the fetus. Journal of Obstetrics and Gynaecology of the British Commonwealth, 79, 782-787.

Commins, B. T. and Lawther, P. J. (1965). A sensitive method for the determination of carboxyhaemoglobin in a finger prick sample of blood. British Journal of Industrial Medicine, 22, 139-143.

Cugell, D. W., Frank, N. R., Gaensler, E. A., and Badger,
T. L. (1953). Pulmonary function in pregnancy; serial observations in normal women. American Review of Tuberculosis, 67, 568-597.

Hawkins, L. H., Cole, P. V., and Harris, J. (1976). Smoking habits and blood carbon monoxide levels. Environmental Research (in press).

Kjeldsen, K. (1969). Smoking and Atherosclerosis. Munksgaard, Copenhagen.

Lily, R. E. C., Cole, P. V., and Hawkins, L. H. (1972). Spectrophotometric measurement of carboxyhaemoglobin. British Journal of Industrial Medicine, 29, 454-457.

Russell, M. A. H. (1974). Realistic goals for smoking and health. Lancet, 1, 254-257.

US Department of Health, Education and Welfare (1973). The Health Consequences of Smoking, p. 4. US Department of Health, Education and Welfare, Washington, D.C.

Wald, N., Howard, S., Smith, P. G., and Kjeldsen, K. (1973). Association between atherosclerotic diseases and carboxyhaemoglobin levels in tobacco smokers. British Medical Journal, 1, 761-765.

Received for publication 11 November 1975

Accepted for publication 23 December 1975

\section{Lead and criminality*}

\section{LOB and P. DESBAUMES}

Institute of Social and Preventive Medicine, Department of Occupational Medicine and Industrial Hygiene, University of Lausanne, and Cantonal Laboratory of Chemistry

Department of Industrial Toxicology, Geneva, Switzerland

In a previous study (Lob and Desbaumes, 1971), we compared the blood and urinary lead levels of two groups of prisoners living in areas which differed with regard to exposure to environmental lead. The analytical method (polarography) for lead determination used by the Laboratory of Industrial Toxicology was found later to give unduly high

*Supported by a grant from the National Commission of Hygiene of Air. results. Unfortunately the blood lead concentrations published in that paper were taken by other authors (Bryce-Smith, 1972; Bryce-Smith and Waldron, 1974a) as supporting the hypothesis relating lead and criminality.

Numerous studies of the influence of lead on children's intelligence and behaviour (Kotok, 1972; David, Clark, and Voeller, 1972; Lin-Fu, 1973; Lansdown et al., 1974; Landrigan et al., 1975) 